\author{
Nature is pleased to name Lyn Evans, the project manager of the Large Hadron Collider, \\ as its 2008 newsmaker of the year.
}

$$
\text { d }
$$

$\mathrm{n}$ its purest form, science stands above the individual. Evidence does not depend on who discovers it, and scientists must willingly give up ideas that evidence does not support.

The world's most powerful particle accelerator - the Large Hadron Collider (LHC) - is a monument to this ethos. Based at CERN, the particle-physics laboratory near Geneva, Switzerland, the collider has faced some tough times - not least of which is an accident that has left the collider out of commission until at least July 2009. Once the damage is repaired, however, thousands of physicists will watch as the massive machine begins to probe some of the most fundamental laws of nature. And they will eagerly test their theories against the collider's output.

Yet the LHC, like science itself, is not just a platonic ideal. It lives because of the very real individuals who believe in its purpose. And one individual stands out in this regard: Lyn Evans. Evans has spent the past decade and a half as the LHC's project manager, a role that has at times required him to be a scientist, diplomat, politician and foreman. His unique blend of political acumen and technical skill has been instrumental in seeing the project through to its completion, and for this reason Nature has singled Evans out as its newsmaker of the year (see page 862 ).

Evans has taken a personal approach to building this imposing collider. His meetings are often small and casual, and he has been known to settle project schedules over a beer. This informal approach has not always worked to the LHC's advantage: a cost increase in 2001 was in part due to poor bookkeeping, and Evans's one-on-one approach sometimes left managers out of the loop.

On balance, however, Evans's mild-mannered but intellectually critical management style and his unfailing optimism have helped see the project through the difficult times to its completion.

Evans should also be recognized for the place he occupies in the social structure of science. In devoting so much of his career to the LHC, he joins a long tradition of scientists who have committed their lives to producing the telescopes, microscopes, accelerators and laboratory methods that others will use to make discoveries. Sometimes the individuals who make these commitments are celebrated; witness this year's Nobel Prize in Chemistry for the development of green fluorescent protein. But more often, they labour in comparative obscurity. Singling out Evans serves as a reminder of the vital importance of these pioneers. Evans is unlikely to be an author on the papers that will someday announce the LHC's breakthroughs, but without him, these discoveries would never have come to pass.

Perhaps because of the diverse roles he has played in his career,
"Lyn Evans exemplifies the spirit that brings truly global scientific imagination to fruition."
Evans seems to appreciate the importance of all the individuals involved in the project. He will happily spend his time chatting with the hundreds of physicists, engineers and shop-floor technicians who have laboured on the LHC's construction. And he will just as happily talk with any of the thousands of politicians, executives and citizens who have supported its completion. Twenty-five nations backed the project, and by some estimates, as many as a billion people watched when the machine circulated its first protons this September.

The LHC is an example of truly global scientific imagination, and Lyn Evans exemplifies the spirit that brings such imagination to fruition. Science may be greater than any one individual, but it is people such as Lyn Evans who allow its progress to continue.

\section{Facilitating the future}

\section{Europe needs a better way to plan, prioritize and fund the next generation of research infrastructure.}

\footnotetext{
A newly released 'roadmap' for Europe's future research infrastructure is, first, a reminder that the continent already has quite a lot of it. The list ranges from the Large Hadron Collider at CERN, the particle-physics laboratory near Geneva, Switzerland, to the five campuses of the European Molecular Biology Laboratory, to the Isaac Newton Group of Telescopes in the Canary Islands near Spain. Such facilities open up research opportunities for scientists across the continent - and are particularly important for tapping the talents of scientists in smaller countries, who generally have less access to the kind of national facilities built by richer nations such as the United Kingdom, France or Germany.
}

Unfortunately, the roadmap is also a reminder that Europe still does not have any systematic way to plan, prioritize or fund these infrastructure projects. Each joint facility to date has been an ad hoc effort, with scientists often working for years to forge a coalition of nations willing to pay for it.

The resulting delays can be costly or even fatal. Biologists warn that life-science infrastructures, such as archives or access to distributed specialist resources, have not kept pace with the progress of the field (see Nature 447, 377-378; 2007). And Earth scientists are beginning to worry about the slow progress in finding partners for Aurora Borealis, a planned $€ 635$-million (US\$870-million) research icebreaker ship, the technical design of which was finalized earlier this month.

The governments of the European Union are aware of the problem. In 2002, they set up the European Strategy Forum on Research Infrastructures (ESFRI), a group of senior science administrators who advise national governments and the European Commission on 